\title{
APLIKASI MONITORING PERLENGKAPAN OPERASIONAL SEKTOR 8 CIRACAS SUDIN PENANGGULANGAN KEBAKARAN DAN PENYELAMATAN
}

\author{
Samsul Bachri ${ }^{1}$, Yuni Wibawanti ${ }^{2}$, Noni Selvia ${ }^{3}$ \\ ${ }^{1,2,3}$ Teknik Informatika,Fakultas Teknik dan Ilmu Komputer, Universitas Indraprasta PGRI \\ Jalan Raya Tengah No 80, Kelurahan Gedong, Pasar Rebo, Jakarta Timur \\ 19aculpluss@gmail.com, ${ }^{2}$ yuniwib206@gmail.com. ${ }^{3}$ nsnpd129@gmail.com
}

\begin{abstract}
ABSTRAK
Sektor 8 Ciracas Sudin Penanggulangan Kebakaran dan Penyelamatan memiliki beberapa sektor permasalahan diantaranya proses monitoring perlengkapan operasional masih manual dengan menggunakan buku besar dalam setiap pencatatannya, sehingga sering terjadi kesalahan-kesalahan dan pembuatan laporan kepada Kepala Seksi Sektor dan proses pengecekan perlengkapan operasional ini dengan cara mengecek satu persatu data operasional sehingga pengecekan tidak efisien. Penelitian ini bertujuan merancang aplikasi monitoring perlengkapan operasional sehingga memudahkan admin dalam memproses pengolahan data dan dapat memonitoring perlengkapan operasional yang ada. Aplikasi yang dibuat menggunakan bahasa pemrograman Java NetBeans 8.0.2 dan penyimpanan data pada database MySQL. Pengembangan sistem yang digunakan Waterfall dengan tahapan rekayasa sistem, analisis, desain, coding, testing, dan maintenance. Hasil dari penelitian ini menciptakan suatu sistem aplikasi monitoring perlengkapan operasional yang dapat memudahkan pihak perusahaan dalam proses pendataan serta mempercepat dalam pencarian data sehingga pelaporan kepada Pimpinan bisa lebih baik dan akurat.
\end{abstract}

Kata Kunci: Aplikasi, Monitoring, Perlengkapan, Operasional, Desktop

\begin{abstract}
Sector 8 Ciracas Sub-dept. of Fire and Rescue Management has several sectoral problems including the process of monitoring operational equipment is still manual by using a ledger in each recording, so that errors often occur and report generation to the Head of the Sector Section and the process of checking this operational equipment by checking one operational data one by one so that checking is not efficient. The purpose of designing a monitoring of operational equipment is to make it easier for admins to process data processing and be able to monitor existing operational equipment. Application devices that have been created with the Java NetBeans 8.0.2 programming language and data storage in the MYSQL database can provide smoothness in the process of inputting and storing data and reports given to the leadership. By using the system development method, namely Waterfall, in this research, the stages are systems engineering, analysis, design, coding, testing, and maintenance. The results of this study create an operational equipment monitoring application system that can facilitate the company in the data collection process and speed up data retrieval so that reporting to the leadership can be better and more accurate.
\end{abstract} Key Word: Application, Monitoring, Equipment, Operational, Desktop

\section{PENDAHULUAN}

Pemerintah membentuk Dinas Pemadam Kebakaran (Damkar) diberbagai wilayah di Indonesia. Setiap Dinas Pemadam Kebakaran (Damkar) terdapat beberapa UPT yang tersebar di daerah-daerah kabupaten/kota. Dinas Pemadam Kebakaran (Damkar) merupakan lembaga penanggulangan bencana yang berkedudukan di bawah dan bertanggung jawab kepada Bupati. Dinas Pemadam Kebakaran dan Penyelamatan adalah perangkat daerah pada pemerintah daerah provinsi dan kabupaten/kota yang menyelenggarakan sub urusan kebakaran. Salah satu perangkat daerah yang dimaksud adalah petugas Pemadam Kebakaran. Petugas Pemadam Kebakaran memiliki tugas pokok yaitu pencegahan kebakaran, pemadam kebakaran dan penyelamatan jiwa dan ancaman kebakaran dan bencana lainnya (Fitriani \& Labani, 2019).

Dalam proses monitoring perlengkapan operasional, Damkar Sektor 8 Ciracas Sudin Penanggulangan Kebakaran dan Penyelamatan Jakarta Timur masih terdapat banyak 
permasalahan. Permasalahan yang paling signifikan adalah pada proses monitoring perlengkapan operasional serta laporan dilakukan dengan cara manual menggunakan buku besar dalam pencatatannya. Sistem yang masih manual memungkinkan untuk terjadinya kehilangan data sangatlah besar, kesulitan untuk menganalisa kesimpulan data, dan kesulitan dalam hal monitoring (Cahyadi Putra \& Mahendra, 2020).

Data yang didapat seringkali bermasalah karena kesalahan dari manusia, misalnya ketika bagian administrasi membutuhkan informasi mengenai perlengkapan operasional maka harus dilakukan pengecekan ke gudang dan melakukan pengontrolan perlengkapan operasional. Pelaporan sering sekali terlambat pada saat penyerahan laporan bulanan kepada Kepala Seksi Sektor.

Monitoring merupakan proses untuk menjamin tercapainya tujuan-tujuan organisasi dan manajemen. Hal ini berkaitan dengan cara dalam membuat kegiatan-kegiatan yang sesuai dengan rencana (Meisak, 2017). Jadi, Monitoring adalah kegiatan penilaian pola kerja yang dilakukan dengan cara mengkaji maupun mengamati kesesuian suatu kegiatan yang dilaksanakan dengan rencana (Rohayati, 2014).

Dengan permasalahan tersebut, perlu ada nya suatu sistem yang terkomputerisasi dalam penyelesaiannya. Sistem adalah sekelompok unsur yang salaing berkaitan dan berfungsi secara bersama untuk mencapai tujuan (Sutabri, 2012). Sistem merupakan suatu kumpulan dari beberapa komponen yang membentuk satu kesatuan (Tyoso, 2016). Pembangunan sistem adalah sekumpulan aktivitas yang menggambarkan secara rinci bagaimana sistem akan berjalan. Pembangunan sistem bertujuan untuk menghasilkan produk perangkat lunak yang sesuai dengan kebutuhan user (Satzinger, J. W., Jackson, R. B., Burd, n.d.).

Dengan adanya suatu sistem informasi diharapkan dapat menangani permasalahan yang ada pada perusahaan tersebut. Sistem terdiri dari beberapa obyek, atau unsur, atau komponen yang saling berhubungan sehingga merupakan satu kesatuan pemrosesan atau pengolahan yang tertentu. (Prasojo, 2011)
Perancangan suatu sistem diperlukan dimana divisi lain dapat dengan mudah melakukan proses permintaan perlengkapan peralatan kantor, setelah dilakukan proses permintaan maka admin purchasing dapat memproses permintaan tersebut, sehingga permasalahan yang sering terjadi, dalam proses permintaan perlengkapan peralatan kantor tersebut tidak terjadi kembali. System dirancang khusus agar dapat membantu menyelesaikan pembuatan laporan tanpa harus menulis atau mengetik kembali hasil permintaan perlengkapan peralatan kantor, sistem ini akan secara otomatis dalam melakukan permintaan perlengkapan peralatan kantor yang dapat memudahkan dalam membuat laporan permintaan perlengkapan peralatan kantor otomatis dan pemantauan pesanan yang belum dikirim (Maimunah, Jawahir, \& Marina, 2019).

Perancangan aplikasi ini dapat memberikan kemudahan pekerjaan bagi admin dalam proses penginputan, pencarian data serta mempercepat dalam melaksanakan pembuatan laporan dan dapat memudahkan perusahaan dalam proses monitoring perlengkapan operasional pada Sektor 8 Ciracas Sudin Penanggulangan Kebakaran dan Penyelamatan Jakarta Timur.

\section{METODE PENELITIAN}

Peneliti menggunakan metode Research and Development dalam penyelesaian penelitian ini. Metode penelitian ini dapat digunakan untuk menghasilkan produk tertentu, dapat dalam bentuk perangkat lunak (software) (Sugiyono, 2016). Dalam hal ini penelitian yang dilakukan dengan merancang suatu perangkat lunak ataupun sistem informasi monitoring perlengkapan operasional pada Sektor 8 Ciracas Sudin Penanggulangan Kebakaran dan Penyelamatan Jakarta Timur yang sesuai dengan kebutuhan.

Dalam penelitian $\mathrm{R} \& \mathrm{D}$, ada beberapa metode yang digunakan yaitu metode deskriptif, evaluatif dan eksperimental. Metode penelitian deskriptif digunakan dalam penelitian awal untuk menghimpun data tentang kondisi yang ada yaitu penulis membutuhkan data-data yang dapat menunjang tercipta nya suatu sistem informasi monitoring perlengkapan operasional seperti data peralatan operasional, data peralatan rusak, data 
permintaan peralatan, dan data penerimaan peralatan terdahulu yang masih tersimpan secara manual didalam buku besar. Metode evaluatif digunakan untuk mengevaluasi proses ujicoba pengembangan suatu produk, dalam proses ini penulis melakukan ujicoba terhadap suatu sistem yang telah dirancang agar tidak ada terjadi kesalahan dalam proses penginputan data serta pelaporan bulanan kepada Kepala Seksi Sektor. Dan metode eksperimen digunakan untuk menguji keampuhan dari produk yang dihasilkan, dalam proses yang terakhir ini perlu dilakukan pengujian akhir yang diharapkan bahwa sistem yang dirancang oleh penulis dapat berjalan dengan baik dan sesuai dengan kebutuhan dan terfokus pada proses monitoring perlengkapan operasional pada Sektor 8 Ciracas Sudin Penanggulangan Kebakaran dan Penyelamatan Jakarta Timur.

\section{HASIL DAN PEMBAHASAN}

\section{Alternatif Penyelesaian Masalah}

Setelah penulis melakukan analisis permasalahan yang dihadapi, diusulkan alternatif penyelesaian masalahnya sebagai berikut:

1. Perancangan sistem informasi pendataan peralatan dibuat terkomputerisasi sehingga informasi menjadi lebih cepat, tepat, dan akurat.

2. Dilakukan pengolahan basis data untuk sistem pendataan peralatan sehingga penyimpanan data tidak menggunakan media kertas, melainkan berupa harddisk atau penyimpanan elektronik lainnya.

3. Membuat sistem pendataan peralatan yang mudah diakses sehingga proses pendataan dan pencarian data menjadi lebih efektif dan efisien.

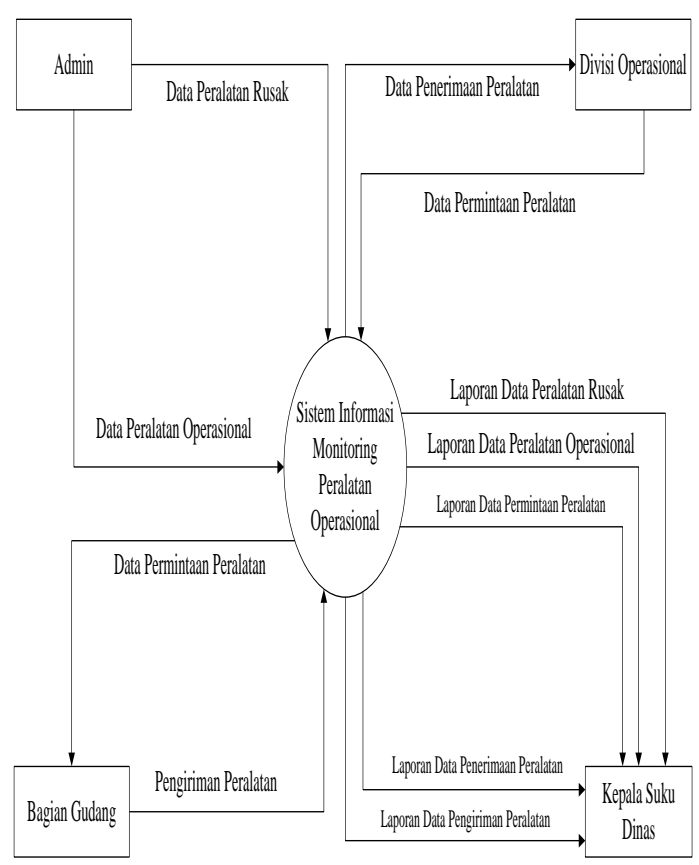

Gambar 1. Diagram Konteks

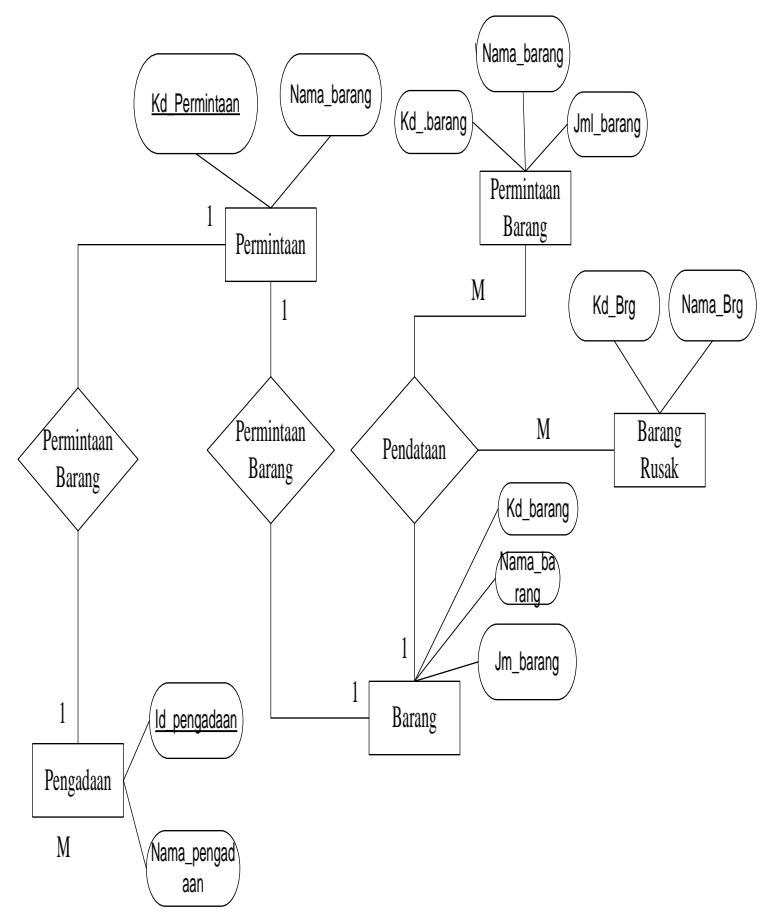

Gambar 2. ERD (Entity Relationship Diagram)

Tampilan layar dan pengujian pada software di buat dengan menggunakan bahasa pemrograman Java. 


\section{Tampilan Layar}

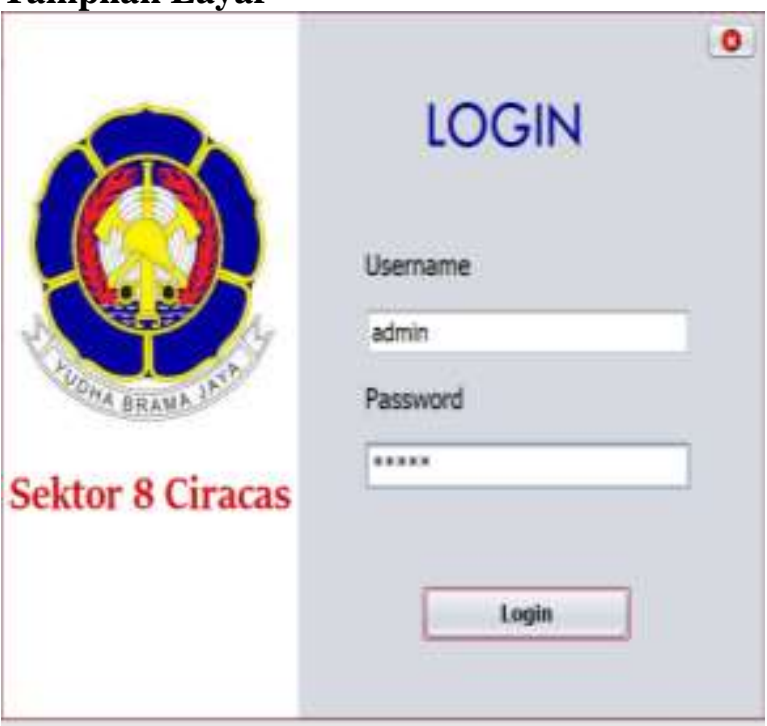

Gambar 3. Form Login

Pada awal program akan tampil form login yang digunakan sebagai kata kunci untuk masuk pada program utama. Dalam Form menu kerahasiaannya tetap terjaga dengan baik sehingga hanya pihak tertentu yang dapat mengakses program ini. Apabila pengguna memasukkan username dan password denagn benar, maka menu utama akan tampil dan program siap untuk dijalankan.

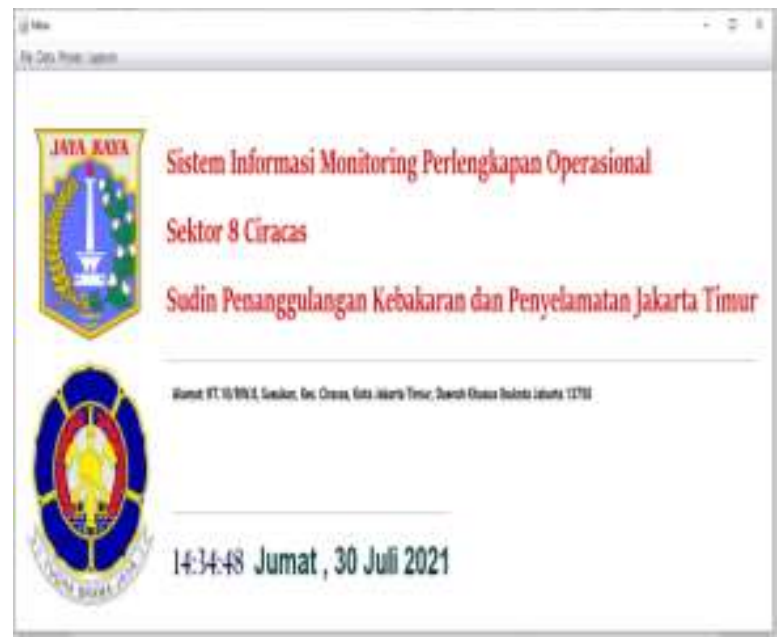

Gambar 4. Form Menu Utama

Layar di atas menampilkan tampilan Menu Utama pada Aplikasi Informasi Monitoring Perlengkapan Operasional. Pada layar utama tersedia menu bar yang terdiri dari master data untuk memasukkan data-data yang berkaitan dengan data jenis alat, data alat operasional, data permintaan alat operasional, data kerusakan alat operasional, data pengiriman alat operasional dan laporan-laporan.

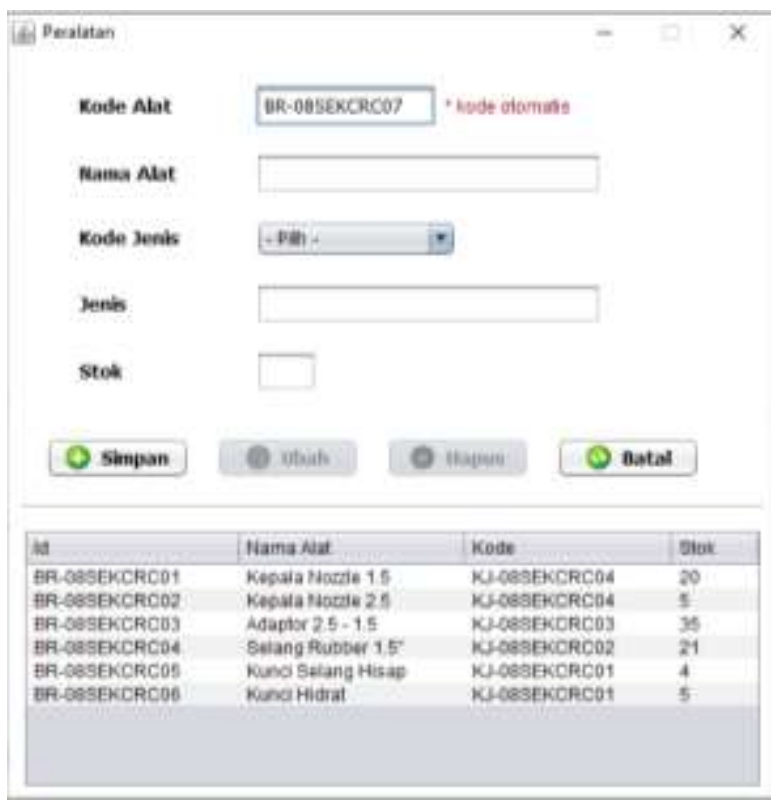

Gambar 5. Form Data Peralatan

Lyar form data peralatan digunakan untuk menginput data peralatan yang terdiri dari Kode Alat, Nama Alat, Kode Jenis, Jenis dan Stok.

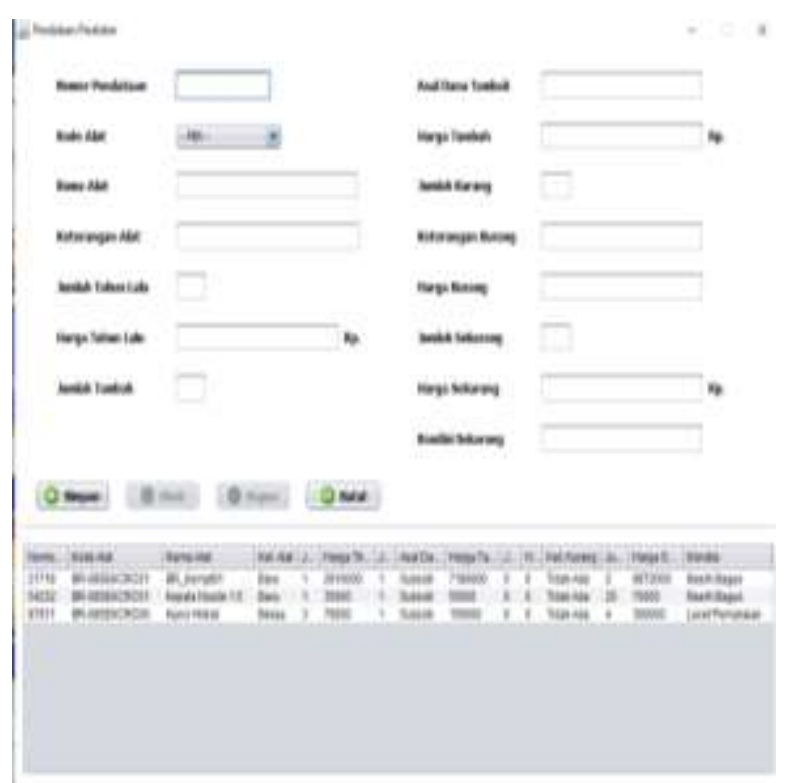

Gambar 6. Form Data Peralatan Operasional

Layar form pendataan peralatan operasional digunakan untuk meng-input peralatan operasional yang terdiri dari Nomor Pendataan, Kode Alat, Nama Alat, Keterangan Alat, Jumlah Tahun Lalu, Harga Tahun Lalu, Jumlah Tambah, 
Asal Dana Tambah, Harga Tambah, Jumlah Alat, Keterangan Alat, Harga Kurang, Jumlah Sekarang, Harga Sekarang dan Kondisi Sekarang.

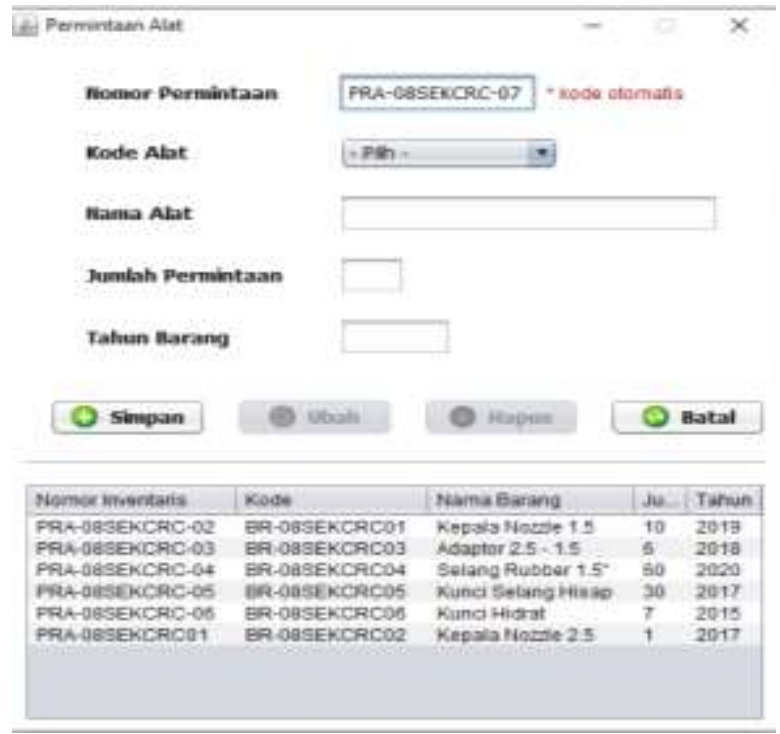

Gambar 7. Data Form Data Permintaan Alat

Layar di atas menampilkan tampilan form data permintaan alat operasional. Pada layar form data permintaan alat operasional untuk menginput data permintaan alat operasional yang terdiri dari Nomor Permintaan, Kode Alat, Nama Alat, Jumlah Permintaan dan Tahun Alat.

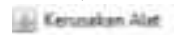

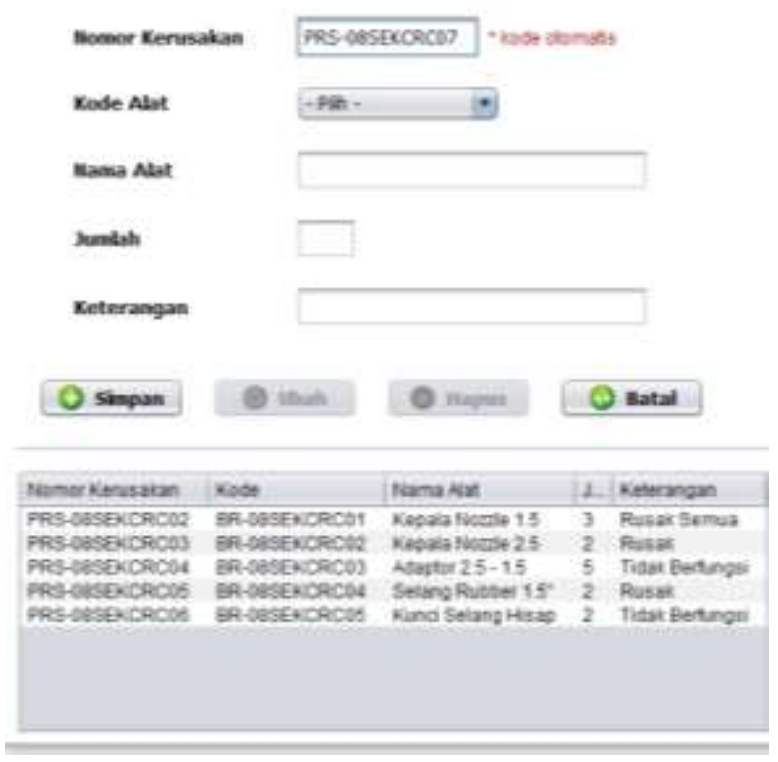

Gambar 8. Form Data Kerusakan Alat

Layar di atas menampilkan tampilan form data kerusakan alat operasional. Form data kerusakan alat operasional digunkan untuk meng-input data kerusakan alat operasional yang terdiri dari Nomor Kerusakan, Kode Alat, Nama Alat, Jumlah dan Keterangan.

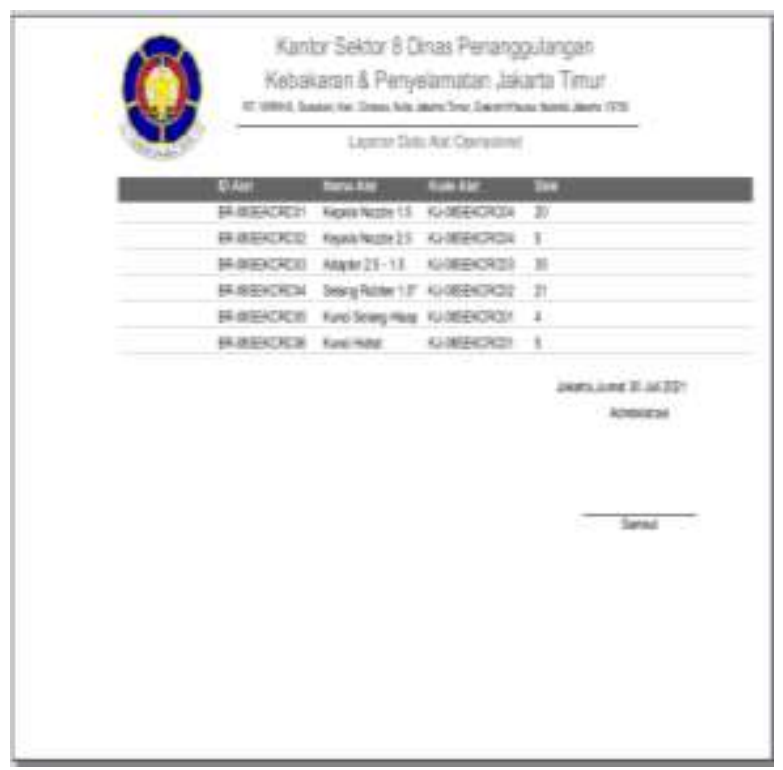

Gambar 9. Laporan Data Alat Operasional

Layar di atas menampilkan tampilan form laporan data alat. Pada layar form data alat digunakan untuk melakukan proses pengecekkan terhadap laporan data alat yang terdiri ID Alat, Nama Alat, Kode Alat, dan Stok.

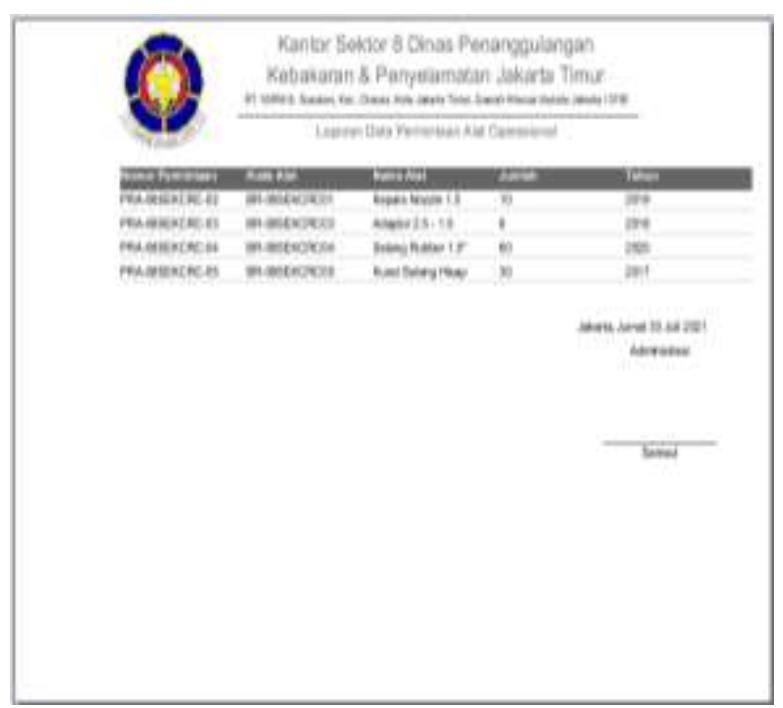

Gambar 10. Laporan Data Permintaan Alat

Layar di atas menampilkan tampilan form laporan data permintaan alat operasional. Pada layar form data permintaan alat operasional digunakan untuk mengecek laporan data alat operasional barang 
terdiri Nomor Permintaan, Kode Alat, Nama Alat, Jumlah dan Tahun.

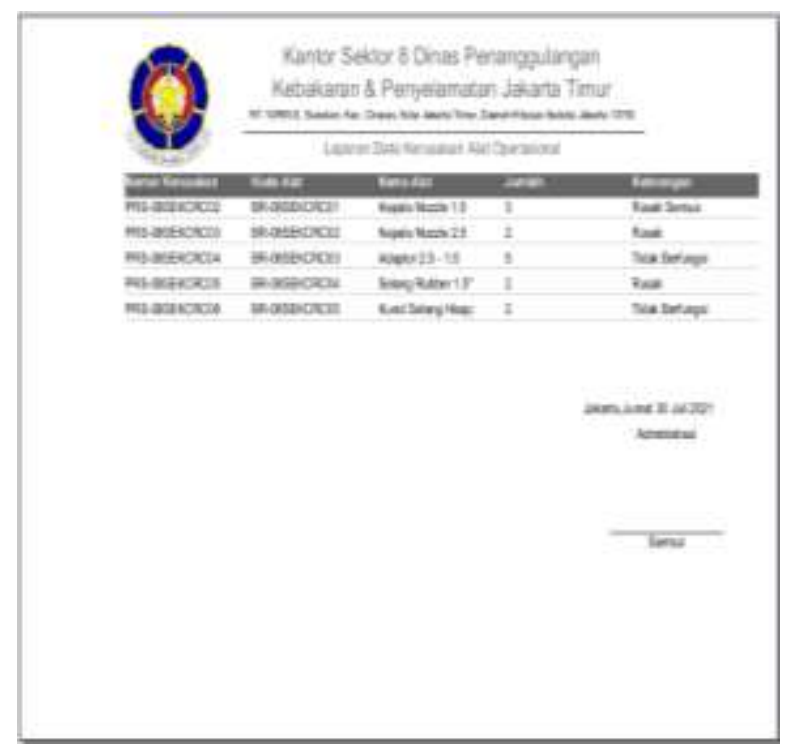

Gambar 11. Laporan Data Kerusakan Alat

Layar di atas menampilkan tampilan form laporan data kerusakan alat operasional. Pada layar form data kerusakan alat operasional digunakan untuk mengecek laporan data kerusakan alat operasional terdiri Nomor Kerusakan, Kode Alat, Nama Alat, Jumlah dan Keterangan.

\section{Hasil Pengujian}

Pengujian pada penelitian ini menggunakan blackbox testing, dilakukan untuk mengetahui bahwa aplikasi dapat dioperasikan sesuai dengan harapan.

Tabel 1. Pengujian Aplikasi

\begin{tabular}{ll}
\hline \multicolumn{1}{c}{ Kasus yang diuji } & \multicolumn{1}{c}{ Status } \\
\hline Halaman login & Berhasil \\
Menu seluruh master data & Berhasil \\
Menu laporan & Berhasil \\
& Berhasil \\
\hline
\end{tabular}

\section{SIMPULAN DAN SARAN}

Aplikasi yang dirancang dapat meminimalisir human error yang sering terjadi dalam proses pendataan manajemen inventaris barang ketika masih menggunakan sistem secara manual. Aplikasi monitoring peralatan operasional yang dirancang hanya sebagai penunjang proses pengolahan data untuk mengefisienkan waktu dan keamanan data.
Saran yang dapat penulis sampaikan adalah aplikasi sistem informasi monitoring peralatan operasional dapat dikembangkan kembali dalam hal desain atau penambahan database sesuai kebutuhan pengolahan data sistem informasi pengelolaan data monitoring.

\section{DAFTAR PUSTAKA}

Cahyadi Putra, I. G. N. A., \& Mahendra, I. B. M. (2020). Pengembangan Aplikasi Monitoring Inventaris Kelas Dengan Sistem Barcode. JELIKU (Jurnal Elektronik Ilmu Komputer Udayana), 8(4), 525. https://doi.org/10.24843/jlk.2020.v08.i04.p1 8

Fitriani, L., \& Labani, R. N. (2019). Rancang Bangun Sistem Informasi Geografis Monitoring Data Kebakaran di Dinas Pemadam Kebakaran. Jurnal Algoritma, 16(1), 27-33. https://doi.org/10.33364/algoritma/v.161.27

Maimunah, M., Jawahir, J., \& Marina, C. (2019). Perancangan Sistem Informasi Monitoring Permintaan Perlengkapan Peralatan Kantor Berbasis Web Pada Pt Tirtanusa Indotama. ICIT Journal, 5(2), 167-180. https://doi.org/10.33050/icit.v5i2.431

Meisak, D. (2017). Analisis Dan Perancangan Sistem Informasi Persediaan Barang Menggunakan Metode FIFO Pada PT.Shukaku Jambi. Mediasisfo, 11(2), 862875.

Prasojo, M. (2011). Pengantar Sistem Informasi Manajemen. bandung: CV. Remadja Karya.

Rohayati, M. (2014). Membangun Sistem Informasi Monitoring Data Inventory Di Vio Hotel Indonesia. Jurnal Ilmiah Komputer Dan Informatika (KOMPUTA), 1(1), 1-8.

Satzinger, J. W., Jackson, R. B., Burd, S. D. (n.d.). System Analysis and Design in A Changing World. USA: Cengage Learning.

Sugiyono. (2016). Metode Penelitian Kuantitatif, Kualitatif dan $R \& D$. Bandung: PT Alfabet.

Sutabri, T. (2012). Analisis Sistem Informasi. Yogyakarta: Andi.

Tyoso, J. S. P. (2016). Sistem Informasi Manajemen. Yogyakarta: DeePublish. 